\title{
Optimizing PEMFC model parameters using ant lion optimizer and dragonfly algorithm: a comparative study
}

\author{
Zainuddin Mat Isa, Norkharziana Mohd Nayan, Mohd Hafiz Arshad, \\ Nor Ashbahani Mohamad Kajaan \\ Centre of Excellence for Renewable Energy (CERE), School of Electrical Systems Engineering, \\ Universiti Malaysia Perlis, Malaysia
}

\begin{tabular}{l}
\hline Article Info \\
\hline Article history: \\
Received Jan 21, 2019 \\
Revised Jul 21, 2019 \\
Accepted Jul 28, 2019 \\
\hline Keywords: \\
Optimizing PEMFC parameters \\
PEMFC model \\
Ant lion optimizer \\
Dragonfly algorithm \\
Metaheuristic algorithm
\end{tabular}

\begin{abstract}
This paper introduced two optimization algorithms which are Ant Lion Optimizer (ALO) and Dragonfly Algorithm (DA) for extracting the Proton Exchange Membrane Fuel Cell (PEMFC) polarization curve parameters. The results produced by both algorithms are being compared to observe their performance. As a results, the ALO shows great performance compared to DA. Furthermore, these results also being compared with the results of the other reported metaheuristics algorithms. The ALO and DA presented competitive results.
\end{abstract}

Corresponding Author:

Zainuddin Mat Isa,

School of Electrical Systems Engineering,

Universiti Malaysia Perlis,

Kampus Pauh Putra, 02600 Arau, Perlis, Malaysia.

Email: zainuddin@unimap.edu.my

\section{INTRODUCTION}

Currently, the attention of using the metaheuristic algorithms in solving engineering problems had increased significantly. These due to they are derivative-free, impose no restrictions on the problem formulation, and can be easily adapted for various real world problems [1-7]. Proton Exchange Membrane Fuel Cell (PEMFC) is a hydrogen based fuel cell. A hydrogen-rich fuel is injected to the anode, and an oxidant which usually use pure oxygen or air is fed through the cathode [8]. It mainly used for portable and mobile application due to it compactness, small in size, low weight with high power density and pollutants free operation $[8,9]$. Obtaining accurate parameters from actual PEMFC directly is important for modelling purpose but difficult due to its complexity. In the past decades, some existing metaheuristic algorithms, such as Differential Evolution Algorithm (DE) [10-12], Artificial Immune System [13], Artificial Bee Colony [14, 15], Particle Swarm Optimization (PSO) [16, 17], Genetic Algorithm (GA) [18, 19], Backtracking Search Algorithm (BSA) [20] and Bird Mating Optimizer (BMO) [21], have been applied in identifying the electrochemical-based model parameters of PEMFC.

Each metaheuristic algorithms have their own attributes and strategies to reach the global optima with minimum number of iteration without entrapping at local optima. This can be achieved with a good balancing between the exploration and exploitation processes. However, according to No Free Lunch Theorem for optimization [22], a single method cannot fit to every optimization problems. This leads to the application of new algorithm in solving the optimization problem. In this paper, two optimization algorithms, proposed by Mirjalili, the Ant Lion Optimizer algorithm (ALO) [23] and Dragonfly Algorithm (DA) [24] were exploited to extract the PEMFC electrochemical-based model parameters. The ALO 
is simulating the hunting mechanism of antlions, meanwhile the DA simulate the static and dynamic swarming behaviors of dragonflies in nature. The performance of both algorithms in obtaining the parameters of PEMFC stack are compared and analyzed with subsequent discussions The Ballard Mark V PEMFC (BM5), as being reported and used in many literatures [10, 20, 21, 25, 26], is used as the test bench. Furthermore, the best results is then being compared with other algorithms reported in the literature to observe their real performance.

The remainder of this paper is organized as follows: Mathematical Modelling of Polarization Curve Section which represent the PEMFC mathematical model using electrochemical model and Problem Formulation Section describe the objective function selected for optimization process. In Optimization Algorithm Section, the ALO and DA are briefly described. In Optimization Results Section, the performance of both algorithms in determining the PEMFC model parameters are observed and discussed. Then, the best results are compared with other optimization approaches. Finally, the conclusion and future research are drawn in Conclusions Section.

\section{MATHEMATICAL MODELLING OF POLARIZATION CURVE}

This paper adopted the basic model from [27], where three (3) different kinds of voltage drops are taken for the model development. The output voltage for a PEMFC cell stack $V_{\text {cell }}$ is calculated as [28]:

$$
V_{\text {cell }}=N_{s} \times\left(E_{\text {Nernst }}-V_{\text {act }}-V_{\text {con }}-V_{\text {ohmic }}\right)
$$

where Ns is the number of cell in a stack, $E_{\text {Nernst }}$ is the reversible fuel cell voltage. Meanwhile, the $V_{a c t}$, $V_{c o n}$, and $V_{\text {ohmic }}$ are the voltages drop due to activation losses at the lower currents, concentration voltage losses at higher currents, and the ohmic losses at the intermediate currents, respectively. The $E_{\text {Nernst }}$ can be obtained as follows:

$$
E_{\text {Nernst }}=1.229-0.85 \times 10^{-3}(T-298.15)+4.31 \times 10^{-5} \times\left(\ln \left(P_{H_{2}}\right)+0.5 \ln \left(P_{O_{2}}\right)\right.
$$

where $\mathrm{P}_{\mathrm{H}_{2}}$ and $\mathrm{P}_{\mathrm{O}_{2}}$ are correspondingly partial pressures of hydrogen and oxygen in atm while $\mathrm{T}$ represents the cell temperature in Kelvin.

The $V_{\text {act }}$ is defined as [10]:

$$
V_{a c t}=-\left[\xi_{1}+\xi_{2} T+\xi_{3} T \ln \left(C_{O_{2}}\right)+\xi_{4} T \ln (i)\right]
$$

where $\xi_{1}, \xi_{2}, \xi_{3}$ and $\xi_{4}$ are the semi-empirical coefficients and $i$ is the cell current. $C_{O_{2}}$ is the oxygen concentration $(\mathrm{mol} \mathrm{cm}-3)$ in the cathode interface and defined as:

$$
C_{O_{2}}=\frac{P_{O_{2}}}{5.08 \times 10^{6} \times e^{-(498 / T)}}
$$

The $V_{\text {ohmic }}$ can be calculated by:

$$
V_{\text {ohmic }}=i \times\left(R_{M}+R_{C}\right)
$$

where $R_{M}$ and $R_{C}$ are the equivalent membrane resistance $(\Omega \mathrm{cm} 2)$ and the contact resistance $(\Omega \mathrm{cm} 2)$ between electrodes and membrane as well as the electrodes and bipolar plates, respectively [26]. $R_{M}$ is defined as:

$$
R_{M}=\frac{\rho_{M} \times \ell}{A}
$$


where $\rho_{M}$ is the specific membrane resistivity $(\Omega \mathrm{cm})$ and $\ell$ is the membrane thickness $(\mathrm{cm})$ that acts as a cell electrolyte while $A$ is the active cell area $(\mathrm{cm} 2)$. The $\rho_{M}$ value can be obtained using as follows:

$$
\rho_{\mathrm{M}}=\frac{181.6\left[1+0.03\left(\frac{i}{A}\right)+0.062\left(\frac{T}{303}\right)^{2}(i / A)^{2.5}\right.}{\left[\lambda-0.643-3\left(\frac{i}{A}\right) \exp \left[4.18\left(\frac{T-303}{T}\right)\right]\right.}
$$

where $\lambda$ is an adjustable parameter that related to the water content of the membrane. Finally, the $V_{\text {con }}$ is defined as:

$$
V_{c o n}=-b \ln \left(1-\frac{J+J_{n}}{J_{\max }}\right)
$$

where $b$ is the parametric coefficient, $J$ is the current density $(\mathrm{A} \mathrm{cm}-2), J_{\max }$ is the maximum current density (A cm-2) and $J_{n}$ is internal current density due to fuel crossover and internal currents [14]. Most of the time, $J_{n}$ can be neglected since it value is very small, however, Correa et al. [29] stated that $J_{n}$ has a considerable effect on the model results especially at lower currents. Therefore, $J_{n}$ is being considered in the calculation in this paper.

\section{PROBLEM FOMULATION}

Based on the stated equations in section 2, there are 11 unknown parameters involved in describing the PEMFC operation. These unknown parameters are $\xi_{1}, \xi_{2}, \xi_{3}, \xi_{4}, A, \ell, R_{c}, J_{n}, J_{\max }, b$, and $\lambda$. A performance criterion or an objective function is defined for an optimization purpose. In this work, the mean square error (MSE) between the output voltage of the actual PEMFC stack and the model output voltage are used as the objective function [10]:

$$
M S E=\frac{1}{N} \sum_{j=1}^{N}\left(V_{i, m}-V_{i}\right)^{2}
$$

where $V_{i, m}$ is the measured output voltage of the actual PEMFC stack, $V_{i}$ is the model output voltage, and $N$ is the number of the experimental data point.

\section{OPTIMIZATION ALGORITHM}

In this part, the ALO and DA are being described briefly. Both algorithms were introduced by Mirjalili in 2015. The Ant Lion Optimizer is a heuristic optimization algorithm that mimics the hunting mechanism of antlions in nature. Five main steps of hunting prey such as the random walk of ants, building traps, entrapment of ants in traps, catching preys, and re-building traps are implemented. Figure 1 shows the flowchart of the ALO. Details description of the process can be referred to [23].

The DA was initiated from the static and dynamic swarming behaviors of dragonflies in nature [24]. The exploration and exploitation phases are designed by modeling the social interaction of dragonflies in navigating, searching for foods, and avoiding enemies when swarming in dynamically or statistically [24, 30]. There are five factors involved in determining the individual dragonfly position [24, 30, 31]:

a. The static collision avoidance of the individuals from other individuals in the neighborhood (separation).

b. The velocity matching of individuals to other individuals in the neighborhood (alignment).

c. The tendency of individuals towards the center of the mass of the neighborhood (cohesion).

d. Attracted towards food sources

e. Distracted outward enemies 
The flow of the DA execution is summarizes in Figure 2. Details explanation of the execution processes can be referred to original paper by Mirjalili [24].

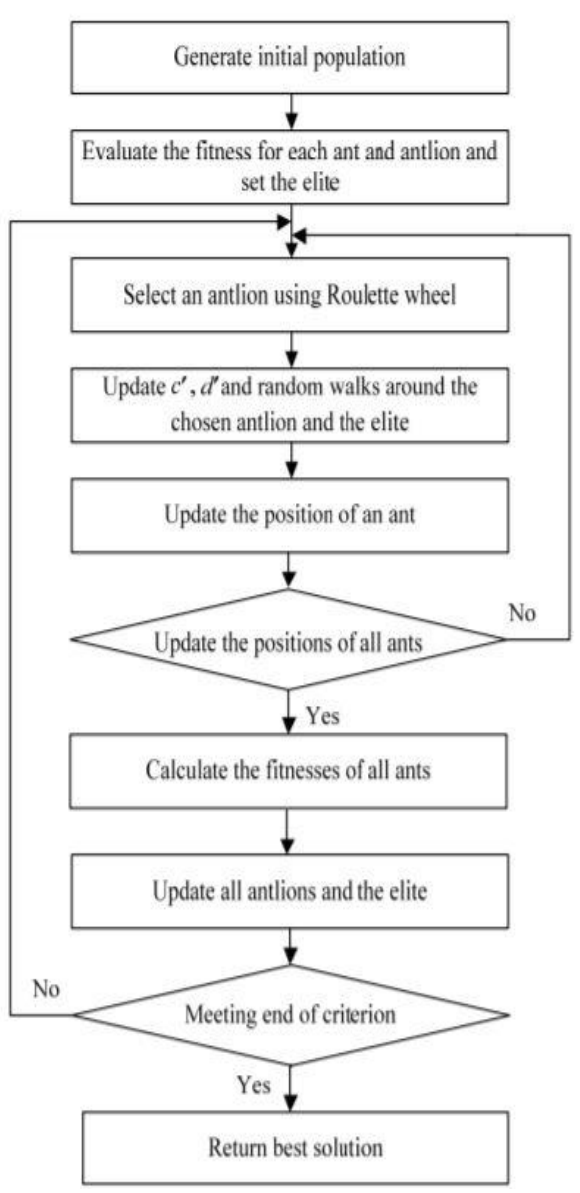

Figure 1. Flowchart of the ant lion optimizer algorithm

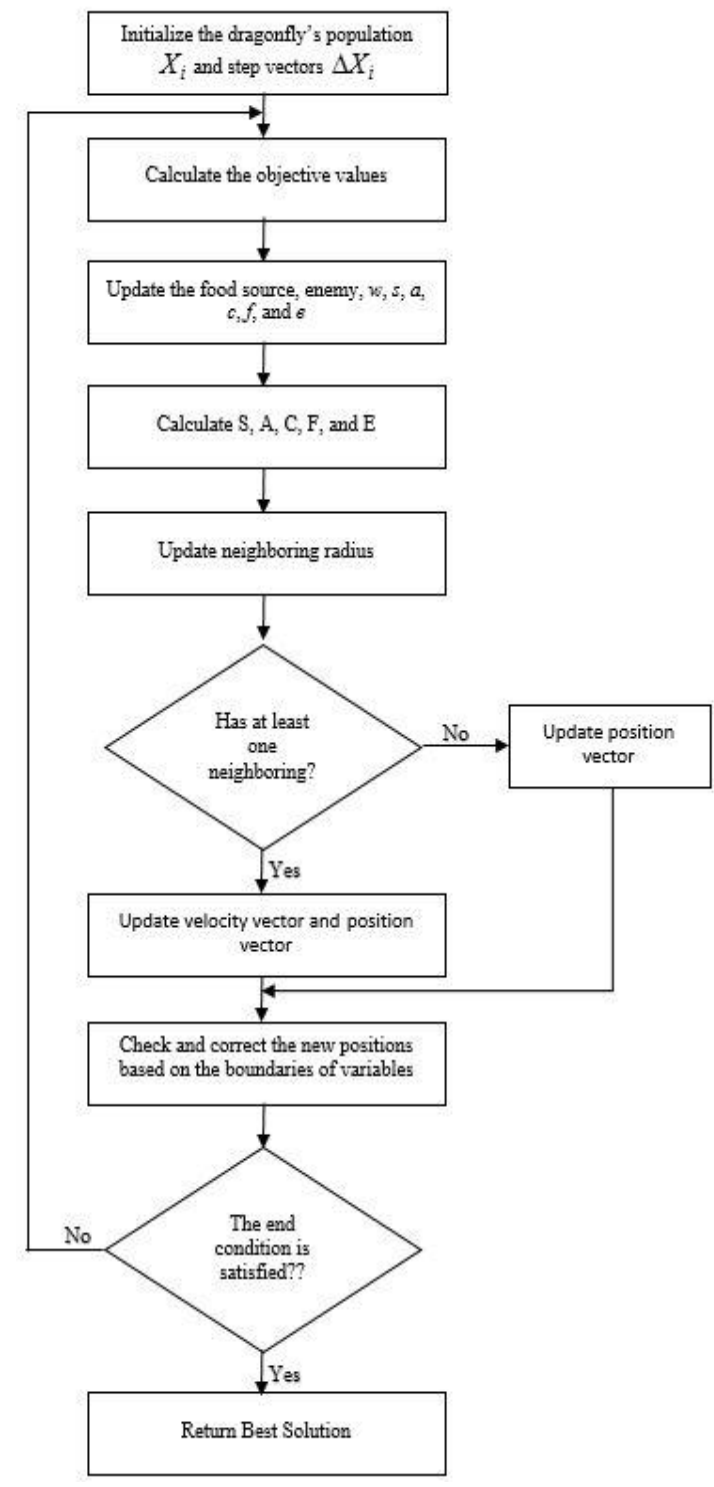

Figure 2. Flowchart of the dragonfly algorithm

\section{RESULTS AND ANALYSIS}

A single cell Ballard Mark V PEMFC, extracted from [10] is chosen to evaluate the optimization capability of ALO and DA. Simulation have been done using Intel ${ }^{\circledR}$ Core ${ }^{\mathrm{TM}}$ i5 processors with MATLAB version 2017. In this work, there are 11 unknown parameters of PEMFC required to be optimized. The ranges of these parameters are shown in Table 1. Before implement both algorithms in MATLAB software, the adjustable parameters need to be tuned. The setup similar with work done by A.Askarzadeh [20] was adopted; the population size is set to 30 and the maximum number of iteration is equal to 2000 . The algorithm is executed 50 times for each fuel cell in order to get the best objective function optimal value.

Table 1. Search range of the unknown parameters to be optimized

\begin{tabular}{cccccccccccc}
\hline Parameter & $\xi_{1}$ & $\xi_{2}$ & $\xi_{3}$ & $\xi_{4}$ & $\lambda$ & $R_{c}(\Omega)$ & $\mathrm{B}(\mathrm{V})$ & $J_{n}\left(\mathrm{~mA} / \mathrm{cm}^{2}\right)$ & $J_{\max }\left(\mathrm{mA} / \mathrm{cm}^{2}\right)$ & $\ell(\mu m)$ & $A\left(\mathrm{~cm}^{2}\right)$ \\
\hline Lower Bound & -1.1997 & 0.001 & $3.60 \mathrm{E}-05$ & $-2.60 \mathrm{E}-04$ & 10 & 0.0001 & 0.0136 & 1 & 500 & 20 & 20 \\
Upper Bound & -0.8532 & 0.005 & $9.80 \mathrm{E}-05$ & $-9.54 \mathrm{E}-05$ & 24 & 0.0008 & 0.5 & 30 & 1500 & 200 & 100 \\
\hline
\end{tabular}


Figure 3 display the tabulation of best objective value for 50 runs of a single cell BM5 obtained for ALO and DA. Observing this figure, it is clearly being seen that ALO produced better results (low error generated) compared to DA (45 out of 50). This is proved by calculated mean value. The ALO mean value is 3.2610e-5 which is lower than mean value for DA (4.2924e-5). Examine further, the results produced by ALO are more stable and precise which are closed to each other except for run no 2 and 18 which quite rare and can be neglected. In addition, in order to compare the significance difference between these two algorithms, the nonparametric Wilcoxon rank sum test was used [32]. The significance level is set to 5\% $(\alpha=0.05)$. The null hypothesis $\left(h_{0}\right)$ assumes that there is not exists a significant difference between the ALO and DA. However, the obtained p-value (3.9946e-13) is below the significant level, proving that the results of ALO is statistically significant.

The convergence curves of the best objective value for both algorithms are shown in Figure 4. Even though ALO and DA entrapped at local optima for a few times, however, they are able to escape to obtain the global optimum. Moreover, even though the DA converges faster in early iteration, however, the ALO has better adjustment and increase it convergence speed after 200 iterations. This capability leads to the better solution produced by ALO compared to DA. Furthermore, the I-V curves are plotted using the parameters obtained for the best objective function together with the experimental values. Figure 5 shows the I-V curve for BM5. Observing the figure it can been seen that the curve generated using parameters attained by ALO and DA are in good arrangement with the experimental data.

With the intention of further understanding the performance of ALO and DA, the obtained results are compared with the reported results presented in Ref. [10], the same PEMFC model with 11 unknown parameters have been used. In Ref. [10], the parameters identified using Transferred Adaptive Differential Evolution (TRADE), Bird Mating Optimizer (BMO), Backtracking search optimization algorithm (BSA), and Burger's chaotic map (BSABCM-3) are stated. The extracted parameters and their corresponding objective function values for BM5 are displayed in Table 2. Observing the results in Tables 2 clearly reveal that the MSE obtained by both algorithms are smaller compared with other four methods in Ref. [10]. This reveals the better accuracy and the efficiency of the proposed method.

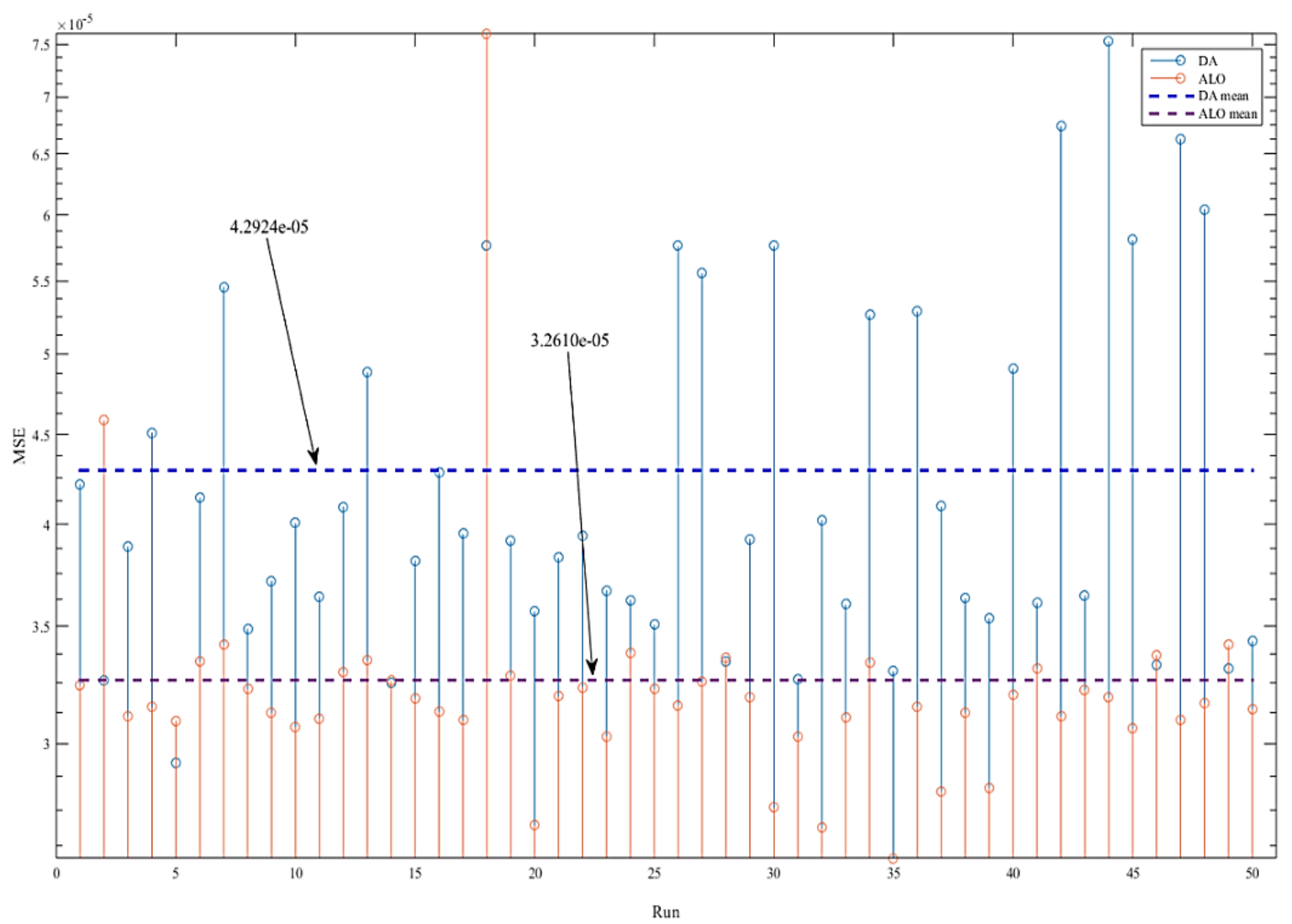

Figure 3. The tabulation of best objective value (MSE) obtained for Ballard Mark V PEMFC in 50 runs 


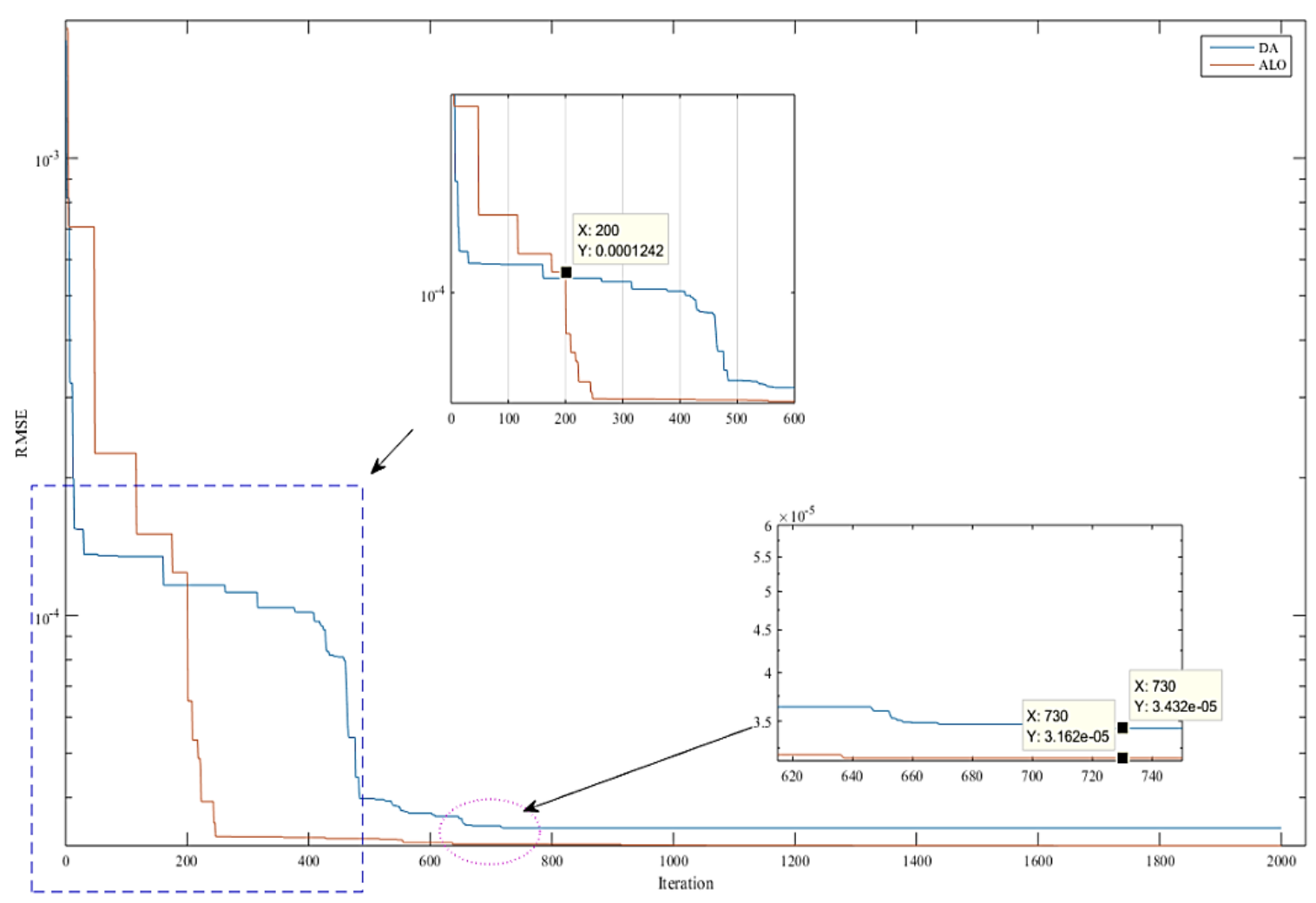

Figure 4. The best objective value convergence curve for Ballard Mark V PEMFC

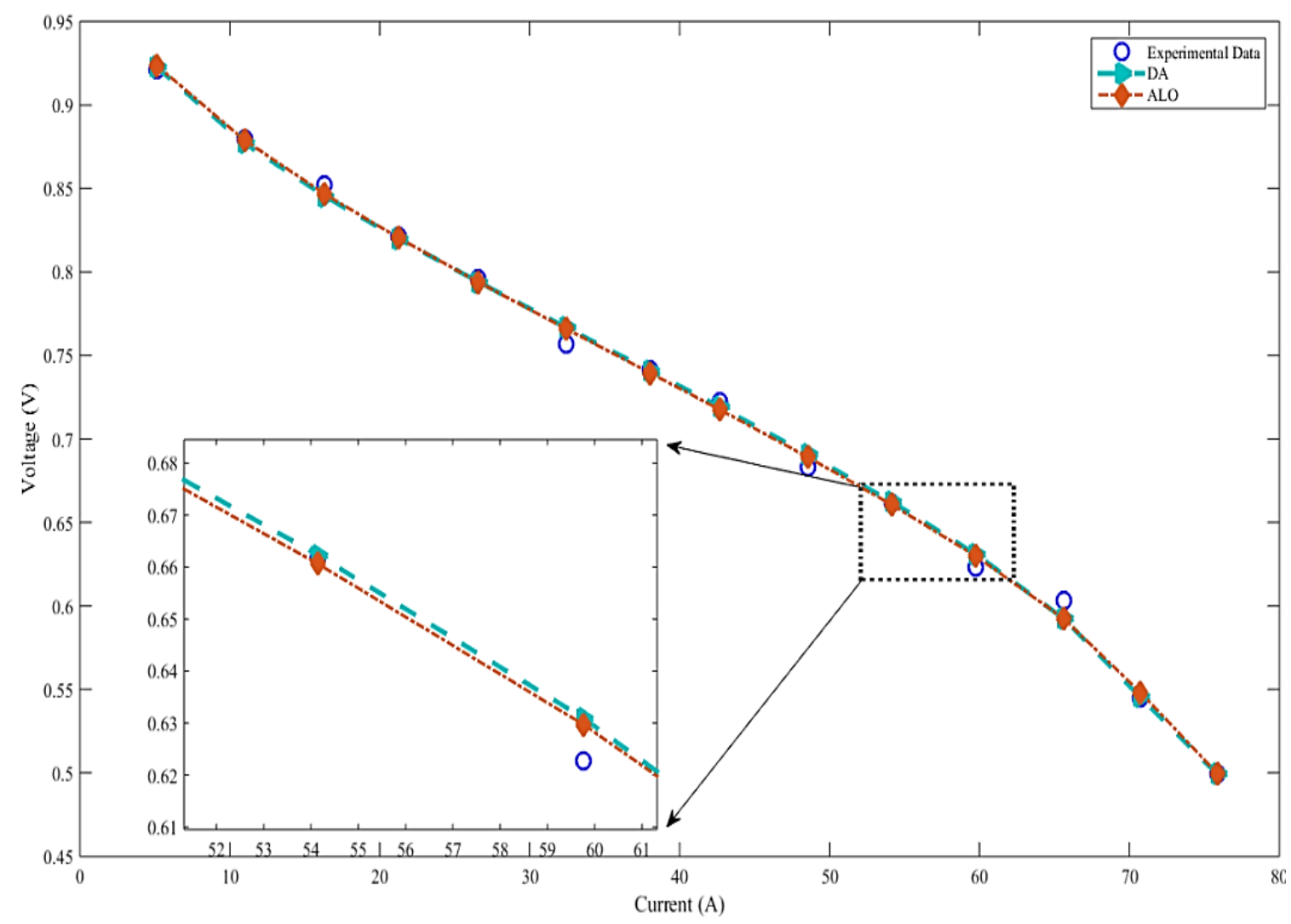

Figure 5. I-V curve for Ballard Mark V PEMFC 
Table 2. Parameters value and operation condition of Ballard Mark V PEMFC stack

\begin{tabular}{|c|c|c|c|c|c|c|}
\hline Parameter & TRADE & $\mathrm{BMO}$ & BSA & BSABSM-3 & DA & ALO \\
\hline$\xi_{1}$ & -1.19611 & -1.081107 & -1.16954 & -1.09537 & -0.90196 & -0.85518 \\
\hline$\xi_{2}$ & 0.004153 & 0.003311 & 0.003612 & 0.003623 & 00035595 & 00031199 \\
\hline$\xi_{3}$ & $7.684 \mathrm{E}-5$ & 4.239E-5 & $5.671 \mathrm{E}-5$ & $5.927 \mathrm{E}-5$ & $9.800 \mathrm{E}-5$ & $7.2947 \mathrm{E}-5$ \\
\hline$\xi_{4}$ & $-1.504 \mathrm{E}-4$ & $-1.469 \mathrm{E}-4$ & $-9.540 \mathrm{E}-5$ & $-1.192 \mathrm{E}-4$ & $-1.348 \mathrm{E}-4$ & $-1.560 \mathrm{E}-4$ \\
\hline$\lambda$ & 24 & 21.71831 & 13.92213 & 19.54295 & 14.0211 & 13.0486 \\
\hline$R_{c}(\Omega)$ & 0.0008 & 0.000491 & 0.0008 & 0.000735 & 0.0005923 & 0.0004943 \\
\hline$B(V)$ & 0.072756 & 0.08265 & 0.020932 & 0.024743 & 0.027341 & 0.028672 \\
\hline$J_{n}\left(m A / \mathrm{cm}^{2}\right)$ & 30 & 29.99945 & 1.1147 & 4.07185 & 30 & 29.8682 \\
\hline$J_{\max }\left(m A / \mathrm{cm}^{2}\right)$ & 862.27594 & 1010.70957 & 872.68143 & 1170.406 & 952.8972 & 794.9896 \\
\hline$\ell(\mu m)$ & 199.59871 & 162.26927 & 200 & 176.17291 & 187.8705 & 177.1509 \\
\hline$A\left(\mathrm{~cm}^{2}\right)$ & 100 & 85.52841 & 85.66426 & 63.67867 & 85.0404 & 97.6386 \\
\hline$F_{o b j}$ & $4.2751 \mathrm{e}-5$ & $9.2823 \mathrm{E}-5$ & $8.4986 \mathrm{E}-5$ & $8.4455 \mathrm{E}-5$ & $3.0926 \mathrm{E}-5$ & $2.5833 \mathrm{E}-5$ \\
\hline
\end{tabular}

\section{CONCLUSION}

In this paper, ALO and DA are proposed to extract the optimized parameters of PEMFC electrochemical model which is one of the most popular PEMFC model. The methodology is applied to Ballard Mark V PEMFC. Through the analysis results of both algorithms, reveals that ALO is better than DA. In addition, the accuracy of the optimized parameters is compared with the results reported in the Ref. [10]. Both algorithms produced much lower MSE and can be competent applicants to conquer the complexity of PEMFC parameter estimation problem. However, observing the convergence curve for the best results of each fuel cell reveals that both algorithms are easy to entrap at local optima for short period of time. This will cost the time to reach the global optimum and sometime lead to premature convergence. Nevertheless, ALO shows better efficiency on converging to the objective functions. However, for DA further modification on the parameter selection can be done to improve the converging issue. Furthermore, comparison in Table 2 reveals that ALO and DA have shown promising method on obtaining optimize PEMFC model parameter. Some improvements can be introduced to existing framework of ALO and DA in order to overcomethe aforementioned drawbacks.

\section{ACKNOWLEDGEMENTS}

The author would like to credit University Malaysia Perlis for providing aid through project supervision and permission to use Center of Excellent for Fenewable Energy (CERE), School of Electrical System Engineering facilities and equipment.

\section{REFERENCES}

[1] J. P. Sridhar and R. Prakash, "Multi-objective whale optimization based minimization of loss , maximization of voltage stability considering cost of DG for optimal sizing and placement of DG," Int. J. Electr. Comput. Eng., vol. 9, no. 2, pp. 835-839, 2019.

[2] F. C. K. and H. Vennila, "Economic and Emission Dispatch using Whale Optimization Algorithm (WOA)," Int. J. Electr. Comput. Eng., vol. 8, no. 3, p. 1297, 2018.

[3] S. R. A. Rahim, I. Musirin, M. M. Othman, and M. H. Hussain, "Multiple DG planning considering distribution loss and penetration level using EMEFA-ANN method." Indones. J. Electr. Eng. Comput. Sci., vol. 7, no. 1, pp. 1-8, 2017.

[4] M. Ahmed, A. Elhassane, and A. Mohamed, "Modelling and Passivity-based Control of a Non Isolated DC-DC Converter in a Fuel Cell System," Int. J. Electr. Comput. Eng., vol. 8, no. 5, pp. 3436-3443, 2018.

[5] P. Hemavathi and A. N. Nandakumar, "Novel Bacteria Foraging Optimization for Energy-efficient Communication in Wireless Sensor Network," Int. J. Electr. Comput. Eng., vol. 8, no. 6, pp. 4755-4762, 2018.

[6] I. G. P. S. Wijaya, K. Uchimura, and G. Koutaki, "Traffic Light Signal Parameters Optimization using Modification of Multielement Genetic Algorithm," Int. J. Electr. Comput. Eng., vol. 8, no. 1, p. 246, 2018.

[7] N. Farhana, A. Hamid, A. Rahim, and J. Selvaraj, "Solar cell parameters identification using hybrid Nelder-Mead and modified particle swarm optimization," J. Renew. Sustain. Energy, vol. 015502, no. 8, pp. 1-22, 2016. 
[8] J. G. Carton, V. Lawlor, A. G. Olabi, C. Hochenauer, and G. Zauner, "Water droplet accumulation and motion in PEM (Proton Exchange Membrane) fuel cell mini-channels," Energy, vol. 39, no. 1, pp. 63-73, 2012.

[9] D. M. Atia, F. H. Fahmy, N. M. Ahmed, and H. T. Dorrah, "A New Control and Design of PEM Fuel Cell Powered Air Diffused Aeration System," TELKOMNIKA (Telecommunication Comput. Electron. Control.), vol. 10, no. 2, pp. 291-302, 2012.

[10] W. Gong, X. Yan, X. Liu, and Z. Cai, "Parameter extraction of different fuel cell models with transferred adaptive differential evolution," Energy, vol. 86, pp. 139-151, 2015.

[11] Z. Sun, N. Wang, Y. Bi, and D. Srinivasan, "Parameter identification of PEMFC model based on hybrid adaptive differential evolution algorithm," Energy, vol. 90, pp. 1334-1341, 2015.

[12] O. E. Turgut and M. T. Coban, "Optimal proton exchange membrane fuel cell modelling based on hybrid Teaching Learning Based Optimization - Differential Evolution algorithm," Ain Shams Eng. J., vol. 7, no. 1, pp. 347-360, 2016.

[13] A. Askarzadeh and A. Rezazadeh, "Artificial immune system-based parameter extraction of proton exchange membrane fuel cell," Int. J. Electr. Power Energy Syst., vol. 33, no. 4, pp. 933-938, May 2011.

[14] W. Zhang, N. Wang, and S. Yang, "Hybrid artificial bee colony algorithm for parameter estimation of proton exchange membrane fuel cell," Int. J. Hydrogen Energy, vol. 38, no. 14, pp. 5796-5806, May 2013.

[15] A. Askarzadeh and A. Rezazadeh, "A new artificial bee swarm algorithm for optimization of proton exchange membrane fuel cell model parameters," J. Zhejiang Univ. Sci. C, vol. 12, no. 8, pp. 638-646, Aug. 2011.

[16] R. Salim, M. Nabag, H. Noura, and A. Fardoun, "The parameter identification of the Nexa 1.2 kW PEMFC's model using particle swarm optimization," Renew. Energy, vol. 82, pp. 26-34, 2015.

[17] Z. M. Isa and N. A. Rahim, "PEM fuel cell model parameters optimization using modified particle swarm optimization algorithm," IEEE Conf. Clean Energy Technol., no. 4, pp. 442-445, 2013.

[18] Q. Zhu, N. Wang, and L. Zhang, "Circular genetic operators based RNA genetic algorithm for modeling proton exchange membrane fuel cells," Int. J. Hydrogen Energy, vol. 39, no. 31, pp. 17779-17790, 2014.

[19] N. Rajasekar, B. Jacob, K. Balasubramanian, K. Priya, K. Sangeetha, and T. Sudhakar Babu, "Comparative study of PEM fuel cell parameter extraction using Genetic Algorithm," Ain Shams Eng. J., vol. 6, no. 4, pp. 1187-1194, 2015.

[20] A. Askarzadeh and S. Coelho, "A backtracking search algorithm combined with Burger' s chaotic map for parameter estimation of PEMFC electrochemical model," Int. J. Hydrogen Energy, vol. 39, no. 21, pp. 11165-11174, 2014.

[21] A. Askarzadeh, "Parameter estimation of fuel cell polarization curve using BMO algorithm," Int. J. Hydrogen Energy, vol. 38, no. 35, pp. 15405-15413, 2013.

[22] D. H. Wolpert and W. G. Macready, "No free lunch theorems for optimization," IEEE Trans. Evol. Comput., vol. 1, no. 1 , pp. 67-82, 1997.

[23] S. Mirjalili, "The ant lion optimizer," Adv. Eng. Softw., vol. 83, pp. 80-98, 2015.

[24] S. Mirjalili, "Dragonfly algorithm: a new meta-heuristic optimization technique for solving single-objective, discrete, and multi-objective problems," Neural Comput. Appl., vol. 27, no. 4, pp. 1053-1073, 2016.

[25] W. Gong and Z. Cai, "Parameter optimization of PEMFC model with improved multi-strategy adaptive differential evolution," Eng. Appl. Artif. Intell., vol. 27, pp. 28-40, 2014.

[26] J. Cheng and G. Zhang, "Parameter fitting of PEMFC models based on adaptive differential evolution," Int. J. Electr. Power Energy Syst., vol. 62, pp. 189-198, 2014.

[27] Z.-J. Mo, X.-J. Zhu, L.-Y. Wei, and G.-Y. Cao, "Parameter optimization for a PEMFC model with a hybrid genetic algorithm," Int. J. Energy Res., vol. 30, no. 8, pp. 585-597, Jun. 2006.

[28] J. M. Corrêa, S. Member, F. A. Farret, V. A. Popov, M. G. Simões, and S. Member, "Sensitivity Analysis of the Modeling Parameters Used in Simulation of Proton Exchange Membrane Fuel Cells," IEEE Trans. Energy Convers., vol. 20, no. 1, pp. 211-218, 2005.

[29] J. M. Corrêa, S. Member, F. A. Farret, L. N. Canha, M. G. Simões, and S. Member, "An Electrochemical-Based Fuel-Cell Model Suitable for Electrical Engineering Automation Approach," IEEE Trans. Ind. Electron., vol. 51, no. 5, pp. 1103-1112, 2004.

[30] K. K. A. Ghany, M. A. Salam, H. M. Zawbaa, E. Emary, K. K. A. Ghany, and B. Parv, "A hybrid dragonfly algorithm with extreme learning machine for prediction A hybrid dragonfly algorithm with extreme learning machine for prediction," no. August, 2016.

[31] T. K. Bashishtha and L. Srivastave, "Nature Inspired Meta-heuristic dragonfly Algorithms for Solving Optimal Power Flow Problem," Int. J. Electron. Electr. Comput. Syst., vol. 5, no. 5, pp. 111-120, 2016.

[32] F. Wilcoxon, "Individual Comparisons by Ranking Methods Author ( s ): Frank Wilcoxon Published by: International Biometric Society Stable URL : http://www.jstor.org/stable/3001968 .," Int. Biometric Soc., vol. 1, no. 6, pp. 80-83, 1945. 


\section{BIOGRAPHIES OF AUTHORS}
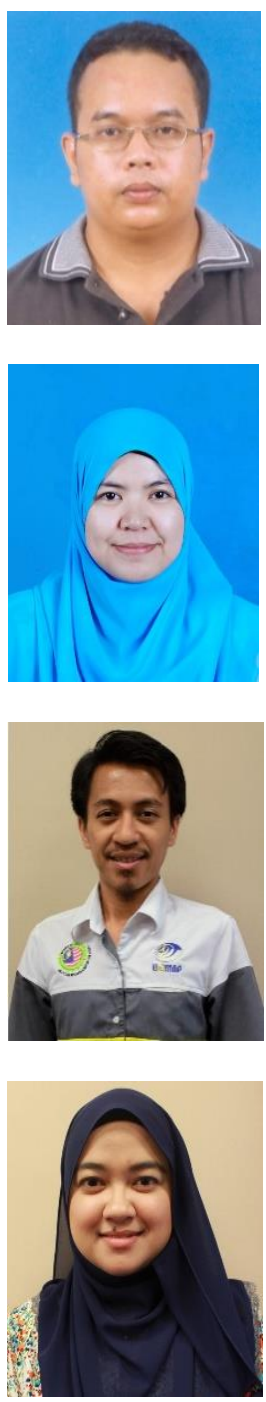

Zainuddin Mat Isa currently works as Senior Lecturer at the School of Electrical Systems Engineering, Universiti Malaysia Perlis. He received her B.Eng Hons (Electrical Power) from Universiti Teknologi Malaysia (UTM) in 2001. After graduation he works as Research Officer at Universiti Teknikal Malaysia Melaka before continuing his master study in M.Sc. (Electrical Engineering) in same university and graduated on 2006. His current research work was on internet on thing application and renewable energy focused on solar energy and fuel cell. Research interest includes Power Electronics fields and Optimization related to metaheuristic algorithm and fuzzy logic.

Norkharziana Mohd Nayan currently works as Senior Lecturer at the School of Electrical Systems Engineering, Universiti Malaysia Perlis. She received her B.Eng Hons (Electrical Power) from Universiti Teknologi Malaysia (UTM) in 2005. After graduation she works as R\&D Engineer in 2006 before continuing her master study in M.Sc. (Electrical and Electronic Engineering) in Universiti Sains Malaysia and graduated on 2009. Her Ph.D Degree was in Electrical Engineering in 2014. Her current research work was on renewable energy focused on harvesting wind and vibration energy. Research interest includes in Power Electronics fields related to Control and Optimization in Machine and Drives.

Mohd Hafiz Arshad currently works as Lecturer at the School of Electrical Systems Engineering, Universiti Malaysia Perlis. He received her B.Eng Hons (Electrical System) from Universiti Malaysia Perlis (UniMAP) in 2008. After graduation he works as Project Engineer in 2009 before continuing his master study in M.Sc. (Electrical System Engineering) in Universiti Malaysia Perlis (UniMAP) and graduated on 2013. His current research work was on power electronics focused on Multilevel Inveter. Research interest includes Renewable Energy.

Nor Ashbahani Mohamad Kajaan currently works as Lecturer at the School of Electrical Systems Engineering, Universiti Malaysia Perlis. She received her B.Eng Hons (Electrical System) and M.Sc. (Electrical System Engineering) from Universiti Malaysia Perlis (UniMAP) in 2009 and 2012 correspondingly. Her research interest includes Power Electronics and Machine Design. 